УДК 378.14.015.3: 159.054

\title{
СОСТОЯНИЕ РОССИЙСКОЙ ТЕРМИНОЛОГИИ ДЛЯ ИННОВАЦИОННОЙ ДЕЯТЕЛЬНОСТИ МОЛОДЁЖИ
}

\author{
Мазуркин П.М.
}

Поволжский государственный технологический университет, Йошкар-Ола, е-таil: kaf_po@mail.ru

\begin{abstract}
Показано, что техническую задачу нужно изложить простыми словами. Это позволяет изобретателю исключить психологический барьер. В итоге образовалась проблема, то есть осознанное противоречие, между методами научного и технического творчества. Поэтому необходимо создать новый тезаурус. Он будет включать такие термины и их определения, которые позволят молодым изобретателям расширить объемы понятий в технике и технологии. С другой стороны, этот словарный запас должен исключить вариации смысла терминов, которые не относятся к научно-техническому творчеству.
\end{abstract}

Ключевые слова: изобретательство, тезаурус, состояние, термины

\section{CONDITION OF THE RUSSIAN TERMINOLOGY FOR INNOVATIVE ACTIVITY OF YOUTH}

\author{
Mazurkin P.M. \\ Volga State Technological University, Yoshkar-Ola,e-mail:kaf_po@mail.ru
}

\begin{abstract}
It is shown that the technical task needs to be stated simple words. It allows the inventor to exclude a psychological barrier. As a result the problem, that is a conscious contradiction, between methods of scientific and technical creativity was formed. Therefore it is necessary to create the new thesaurus. It will include such terms and their definitions which will allow young inventors to expand volumes of concepts of equipment and technology. On the other hand, this lexicon has to exclude variations of sense of terms which don't belong to scientific and technical creativity.
\end{abstract}

Keywords: invention, thesaurus, condition, terms

\begin{abstract}
Модернизачия - обновление, новация - новшество, инновация обновление, нововведение, освоение новшества.
\end{abstract}

Из словарей иностранных слов.

Из многих методов технического творчества известно, что исходно поставленную специалистами техническую задачу нужно изложить простыми словами, понятными для всех. Это позволяет изобретателю в процессе поиска патентоспособных технических решений исключить психологический барьер по данной технической специальности или отрасли производства и потребления. Кроме того, простые слова и термины имеют гораздо больший объем понятий по сравнению с терминами из профессионального жаргона.

Методы научного творчества имеют высокую абстракцию применяемых учеными терминов и определений, и поэтому зачастую только узкий круг избранных может понять друг друга, в особенности в области математики или философии. Этим расширительным или, наоборот, упрощенным (редуцированным) набором терминов и определений, с многозначностью по объему понятий для построения узкопрофессиональных теоретических построений, пользуются и представители технической науки. Достаточно упомянуть о многогран- ности применения слов «техника» и «технология».

В итоге образовалась проблема, то есть осознанное еще немногими противоречие, между методами научного и технического творчества.

Для разрешения проблемы создания методов научно-технического творчества для активизации изобретательской деятельности среди молодежи, прежде всего при подготовке бакалавров и магистров техники и технологии, необходимо создать новый тезаурус. Он будет включать такие термины и их определения, которые позволят для молодых изобретателей расширить объемы понятий в технике (способы и средства не только человека, но и всего живого) и технологии (наука о способах и средствах технического поведения людей, животных, растений). С другой стороны, этот словарный запас должен элиминировать (исключить упрощая) те вариации смысла терминов, которые в настоящее время не относятся к научно-техническому творчеству.

В дальнейшем нижеприведенный набор терминов и их отобранных из словарей разных лет [1-6] за 100-летний период (от словаря В.И. Даля начала XX века и современного толкового словаря русского языка начала XXI века) позволит доходчиво и понятно (на школьном уровне полученных знаний, умений и навыков) изложит пред- 
лагаемые нами методы научно-технического творчества.

Современный толковый словарь русского языка имеет основные недостатки:

1) чрезвычайно политизирован, и из зарубежных слов при их объяснении для применения в русском языке вымыты все нюансы творческого начала личности, дабы планомерно и жестко ограничивая рамки творчества, в особенности художественного, воспитывать и образовывать советского человека Gomo Sovetikus - винтика будущего коммунистического общества, беспрекословно и осознанно подчиняющего свое творческое воображение идеологии коммунистической партии и советского правительства;

2) строгая иерархия министерств и ведомственная разобщенность научно-технической интеллигенции по отраслям науки и техники в нашей стране вызвали резкую обособленность в терминологии, а многие промышленные виды деятельности во многом остались на уровне бытового жаргонизма и всё это перешло в учебники и учебные пособия, которые напрочь отбивают склонности к творчеству и заставляют вызубривать непонятные для представителей из других отраслей по содержательному (эвристическому) смыслу множества конструкций предложений;

3) системный социально-экономический кризис во многом разрушил отраслевые технологические теории, а сами технические способы и средства оказались вообще не конкурентоспособными с зарубежными аналогами и прототипами, в том числе и во многих областях военной техники, считавшейся в СССР ведущей;

4) все известные в нашей стране методы научного и технического творчества возникали из недр военной науки и техники, где цели примитивно просты (как можно больше уничтожить противника) четко определены (Луна предсказуемо движется вокруг Земли) и понятны (нужно обогнать по техническому уровню США), поэтому советским ученым, а не только политикам и властителям, казалось практически возможным неуклонный линейный рост экономики до утопического уровня без импульсно-волновых возмущений социально-экономической системы и циклического развития и роста населения и его благосостояния;

5) методы линейного прогнозирования и теория оказались не нужными, а известные на весь мир отечественные теоретики изобретательства оказались за рубежом, при этом академическая наука оказалась чрезвычайно консервативной и никак не смогла понять необходимость единства и опасности разъединения советскими идеологами так называемой фундаментальной и прикладной науки друг от друга, что привело к отношению академистов как людей белой кости к технарям и техническим новшествам как к плебеям и их творениям.

Можно этот список противоречий продолжить. Однако ясно, что всю систему представлений советских времен нужно перевернуть в сторону личности и мас4имально освобожденной от политической идеологии научно-технической мысли. Все творения, в том числе и идеи в виде различных «ноу-хау» должны быть узаконены как частная интеллектуальная и даже материальная собственность, чтобы чиновники и руководители предприятий не смогли проводить крепостническую технологическую политику, причем нагло выдвигая свои неумные личные аппетиты как государственные интересы.

«Государство - это я». Это личностное определение должно быть на вооружении не только у чиновников и властителей производства и потребления, но оно должно гордо звучать и со стороны творцов науки и техники.

Акт - (от лат. aktus - действие). Единичное проявление какой-либо деятельности; действие, поступок [1, с. 16].

Активация - возбуждение или усиление активности; перевод в деятельное, подвижное состояние $[1$, с. 16]. Возбуждение или усиление активности; перевод в деятельное состояние; переход от состояния покоя к движению, развитию [2, с. 23].

Активизация - (от лат. activus - деятельный). Усиление, оживление деятельности, активности; переход к более подвижному состоянию, к решительным действиям [2, с. 23].

Активность - деятельное участие в чем-либо [1, с. 16]. Энергичная, усиленная деятельность, деятельное состояние; деятельное участие в чем-либо [2, с. 23].

Активный - деятельный, энергичный. Интенсивный. Действующий, способный действовать, взаимодействовать [1, с. 16]. Активный (от лат. activus - деятельный) деятельный, энергичный; противоположно nассивныли. Действующий, развивающийся [2, с. 23].

Действие - 1. Деятельность (руководство к действию). Мн. Действия. - ий. Поступки, поведение (самовольные действия). 2. Осуществление своих функций (мина замедленного действия, продлить действие договора). 3. Влияние, воздействие (благотворное действие солнца на организм). ... 6. Основной вид математического вычисления (четыре действия арифметики) [1, c. 152-153]. 
Как процесс слово «действие» динамичнее объяснено в словаре В.И. Даля [6, с. 206]. Действие - способность, сила, возможность к действованию. Дела, поступки, деяние, деятельность, все, что делается кем или чем-либо. После продолжительного действия духовные и телесные силь наши требуют покоя. ... . Действительно - в (на) самом деле, истинно, в самой вещи, точно, верно, взабыль, по правде. Действительность [6, с. 206].

Действенный - способный воздействовать на что-либо (действенные мерыл, действенная помощь). Действенность [1, с. 152].

Функция - (от лат. functio). 1. Значение, назначение чего-либо (функция кредита, выполнят функичю администратора). Направление деятельности в соответствии с назначением какой-либо организации, учреждения. задача, обязанность должностного лица и т.п. (функичия кооперации, возложить на комитет функиии контроля) 2. Биол. Работа, производимая органом, организмом как проявление его жизнедеятельности (функиия надпочечников, восстановление нарушенных функиий организма). 3. Матем. Зависимость одних переменных величин о других. Переменная величина, меняющаяся в зависимости от изменения другой величины (аргумента). Тригонометрические функиии. 4. Явление, зависящее от другого и служащее формой его проявления, осуществления (литература признается одной из функиий общественного бытия) [1, с. 899].

Из словарей иностранных слов находим следующее. Функция - (от лат. function исполнение). 1. Обязанность, круг деятельности; назначение, роль; [2, с. 556]. Функция - (от лат. function - отправление, деятельность). 1. деятельность, обязанность, работа; назначение; [3, с. 755]. Технической функцией становится назначение (в прошлом и настоящем) и предназначение (в будущем для проектируемых и изготовляемых технических объектов)

Патент - (от лат. patens (patentis) - открытый, явный). 1. Документ, удостоверяющий официальное признание чего-либо изобретением и право изобретателя на него (получить патент на изобретение). ... [1, c. 499]. Патент - 1. Свидетельство, выдаваемое изобретателю и удостоверяющее его авторство и исключительное право на изобретение; ... [2, с. 375]. Патент - 1. Свидетельство, выдаваемое правительством изобретателю на право исключительного пользования сделанным изобретением; ... $[3$, с. 520-521].

Интеллект - (от лат. intellektus - понятие, рассудок). Мыслительные способно- сти человека, разум, уровень умственного развития (быть равнылм кому-либо по интеллекту) [1, с. 246]. Интеллект - ум, рассудок, разум; мыслительная способность человека [2, с. 201], [3, с. 277].

Изо - первая часть сложного слова (от греч. isos - равный). Вносит значение слова: равный, одинаковый по каким-либо показателям (изолиния, изомеры). Изобилие и пр. (38 терминов) [1, с. 239]. Изо - (гр. isos равный, одинаковый, подобный) - первая составная часть сложных слов, обозначающее равенство или подобие (изолиния, изоmonbl). Изоамплитуды и пр. (63 термина) [2, c. 188]. Изо- (гр. isos равный, одинаковый, подобный) - в сложных словах означает равенство или подобие по форме или назначению: в химии - одинаковый состав соединений при разном их строении, например, масляная или изомасляная кислоты. Изоамплитуды и пр. (59 терминов) [3, с. 258].

Из сравнения трех словарей видно, что за период 1955-2004 годы, то есть за полвека, многие термины иностранного происхождения в русском языке претерпели сильнейшую редукцию (упрощение). При этом из исходного объема понятия, принятого в английском языке американской версии переводчиками по указаниям сверху сознательно вымывались те нюансы, которые не подходили или мешали идеологии научного коммунизма.

Это было заметно и по группе слов акт активный. Партии нужны были винтики, которые были бы активными только в рамках жесткой иерархии, поэтому все тонкости терминов, относящиеся к собственности в виде творений отдельных личностей, должны были заменяться упрощенными понятиями без особенностей личностных устремлений, а тем более сомнений, несомненно всегда возникающих в творческой деятельности.

Ведь проблема - это осознанное противоречие, а техническое решение в виде изобретений мировой новизны - это способ ли средство для разрешения этого противоречия. В итоге наша страна за XX век не получила не только открытий на уровне нобелевских лауреатов, но и пассионарная энергия (по Л.Н. Гумилеву) в целом у советско-российских народов была сознательно правителями страны подавлена и открыты только те шлюзы, которые вели к формированию строителя коммунизма.

Таким образом, проблема создания инновационной экономики России ныне находится не в сферах научно-техническом прогрессе, а в наших мозгах с засоренным понятийным аппаратом редуцированного от иностранных слов русского языка. Зато за 
столетие бурно развивалась ненормативная лексика, в особенности среди высших чиновников (даже на селекторных совещаниях Косыгина). Применение матерных слов на производственных совещаниях освобождало начальников от объяснения подчиненным намеченных сверху нововведений.

В итоге рационализаторство и изобретательство стали чем-то бредом фанатиков от техники и технологии. Об этом четко указывали директивные слова всесоюзного старосты М.И. Калинина: нужно изобретать то, что требует социалистическое хозяйство. Железный занавес на творчество, ВТО м числе научное и техническое творчество, был поставлен в умах советских людей задолго до физической берлинской стены.

Изобрести - творчески работая, создать что-либо новое, прежде неизвестное $[1$, с. 239]. Брести - идти медленно или с трудом в определенном направлении $[1$, с. 55]. Изобретут, изобрёл, изобрела, изобрело, изобрели, изобретший, изобретенный, изобретён [4, с. 170]. В словаре В.И. Даля [6, с. 293] нет такого слова, а также неизвестны были и производные слова.

Таким образом, первая часть изо - (гр. isos равный, одинаковый, подобный) и вторая часть «брести» издавна в русском языке имели негативный смысл бредущих медленно в направлении непонятных новшеств. Среди населения изобрести означало «бред», то есть бессмысленные для других, вздорные мысли, речи и т.п.; вздор, чушь.

Вот почему подьячие и чиновники России воспринимали и ныне воспринимают изобретателей не как творцов, по лат. ingenium, то есть как действительно инженеров по определению, (причем слово «инженер» в советское время было полностью опошлено и редуцировано до бессмыслицы типа «инженер по закупкам», как и ныне «менеджер по продажам»), а только как больных с бредовой бессмысленной речью, говорящих и пишущих о чем-то нелепом, бессмысленном для остальных окружающих творца людей.

Этот менталитет «изобреда» создавался столетиями и в средние века изобретателей на Руси просто отправляли на казнь, чтобы другим фанатикам техники неповадно было нести людям крамольную чушь иностранщины.

Изобретатель - тот, кто изобрел или изобретает что-либо [1, с. 239].

Изобретать - - творчески работая, создавать что-либо новое, кому-либо ранее неизвестное. Изобретают, изобретал, изобретает, изобретающий, изобретавший, изобретаемый [4, с. 170].

Изобретательный - находчивый, быстрый на выдумку, способный изобретать.
Свойственный такому человеку [1, с. 239]. Изобретательный (-ая, -ое, -ые, -лен, -льна, -льно, -льны) - находчивый, способный на выдумку, изобретение (изобретательный человек, изобретательный ум) [4, с. 170].

Изобретательство - деятельность изобретателя (изобретателей) [1, с. 239].

Изобретение [1, с. 239]. 1. Изобрести. 2. То, что изобретено; вновь созданный, прежде неизвестный предмет.

В этом определение неясен существенный признак - это уровень новизны или известности изобретения. У итоге в нашей стране в разговорном отношении под изобретением понимается неизвестный для данного человека предмет (устройство или вещество, а о способах как предмете изобретательства даже не упоминают: поэтому понятие «ноу-хау» в России просто не существует, поэтому нет и предмета куплипродажи идей).

Инженерный - технический, связанный с деятельностью инженеров (инженерное сооружение, инженерные войска) [1, с. 244].

Принудительно навязанный синоним «технический» полностью элиминировал (исключил) не только духовно-нравственные черты творческой деятельности в технике и технологии, но и перенес в инженерную деятельность разделение научного от технического. В разговорном языке любого инженера стали обзывать технарем.

В итоге так называемая «фундаментальная» наука резко отграничилась в СССР тремя отдельными сообществами избранных, а пренебрежительная от фундаменталистов, засиживающихся до глубокой старости на своих посиделках и своим старческим маразмом тормозящих научнотехническую деятельность молодых инакомыслящих, от так называемой «прикладной» науки. А представители последней, в свою очередь, также создали свои касты, весьма иронически относящиеся к инженерной деятельности.

Удивителен тот факт, что ВАК все же признал патенты на изобретения как публикации в журналах по своему списку. Значит, что-то в России сдвигается в социальном сознании интеллигенции, если ученые мужи, скрепя сердцами, признали патенты на изобретения и поставили их вровень со своими «фундаментальными» творениями.

Пока в России не будет действенного равенства «изо» между академической и вузовской наукой, а также между ними и технической творческой (инженерной) деятельностью на уровне мировой новизны, нечего и мечтать об инновационной экономике. Но этому существенно мешают подачки в виде надбавок ни за что за научные 
степени: академикам от науки 50, докторам от техники 7, кандидатам технических наук 3 тысячи рублей)

Инновация - (от лат. innovatio - обновление, перемена). 1. Нововведение, новшество (Инновации в управлении). 2. Экон. Комплекс мероприятий, направленных на внедрение в экономику новой техники, технологий, изобретений и т.П.; модернизация. 3. Лингв. Новое, более позднее явление в языке. (Инновациионый, -ая, -ое) [1, с. 245].

Лат. in внутри (иннервация) [2, с. 199]. Поэтому нужно сравнить термин «инновация» со словом «новация». В словарях иностранных слов [2, 3] слово «инновация» отсутствует. Поэтому непонятно, откуда взяли авторы концепции инновационной экономики России до 2020 г. среди четырех «ин» и это понятие. Ведь инновация по своему этимологическому смыслу означает внутри новации, то есть в процессе обновления, изменения.

Новация - (от лат. novatio - обновление, изменение). Новшество, нововведение (вредная новачия, новация в технике) [1, с. 415].

Слово «новация» вообще не было воспринято в нашей стране и на это указывает определение, данное в словаре 1989 г. [2, с. 345]. Новация - (от лат. novatio - обновление, изменение) - в капиталистических странах - прекращение обязательства по соглашению сторон путем замены его новым обязательством (напр., векселя взамен ранее выданного обязательства). Аналогичное определение было дано в словаре 1955 г. [3, с. 482].

Не мудрено, что слово «новация» среди советских чиновников употреблялось как категорический императив, а в лучшем случае без последствий для употребляющего этот термин в критическом или ироническом смысле.

Затем переводчики и их идеологические редакторы согласились слово «новация» употреблять в статике, то есть только как новшество, нововведение. Хотя больше термин новация обозначает процесс обновления и изменения за счет новшеств и нововведений.

Чудны дела твои, ... , но люди не знают, что творят.

Новатор - (лат. novator - обновитель). Человек, который вносит и осуществляет новые идеи, принципы, приёмы и в какойлибо области деятельности (новаторы производства, смельй новатор, новатор по натуре). Новаторский, -ая, - ое [1, с. 415]. В словаре [2, с. 345] новатор - человек, вносящий и осуществляющий новые, прогрессивные принципы, идеи, приемы в какойлибо области деятельности. А в словаре [3, с. 482] еще точнее и подробнее: новатор (лат. novator - возобновитель, обновитель) человек, который смело вводит что-либо, новое, вносит новые прогрессивные идеи в какой-либо области, ломает старые представления, правила, нормы, мешающие движению вперёд (в науке, технике, промышленности, искусстве).

Конечно же, советская система науки и техники считалась наилучшей, поэтому нельзя было допускать в словарях крамолу о смелости, ломке старого и нужды в прогрессивности. К тому же в 50-е годы начался системный кризис тоталитарной экономики. Вот почему мы ныне имеем определение слова «новатор» в виде отстраненной сентенции.

Но оно весьма удачно подходит к преобразованиям начала XXI века.

Новаторство - деятельность новатора (новаторов). Новаторство в технике, новаторство рабочих. Новаторский, -ая, -ое [1, с. 415].

Нововведение - что-либо недавно введенное, принятое (глупое нововведение) [1, с. 415].

Поражает негативное отношение к слову, ведь пример «глупое нововведение» изначально отторгает человека от необходимости творить новое. Но ясно, что термин отображает больше процесс, чем явление.

Новшество - что-либо новое, вновь созданное, примененное и т.п.; нововведение (техническое новшество, новшество в обслуживании населения) [1, с. 416].

Это слово пока по смыслу больше подходит для характеристики явления, чем процесса. Однако по словарю В.И. Даля новшество означает введение новизны.

Новый - такой, который не существовал раньше [1, с. 416].

Возврат к русскому языку начала $\mathrm{XX}$ века, по-видимому, неизбежен и этот позволит освободиться от многих понятийных пут, в особенности по словам из английского языка.

\section{Список литературы}

1. Современный толковый словарь русского языка / гл. ред. С.А. Кузнецов. - М.: Ридерз Дайджест, 2004. $-960 \mathrm{c}$.

2. Словарь иностранных слов. - 18-е изд., стер. М.: Рус. яз., 1989. - 624 с.

3. Словарь иностранных слов. - 5-е изд., стер. М.: Госиздат иностранных и национальных словарей, 1955. -855 c.

4. Сазонова, И.К. Русский глагол и его причастные формы: толковый грамматич. сл. - М.: Рус. яз., 1989. -590 c.

5. Брокгауз, Ф.А. Энциклопедический словарь. Современная версия / Ф.А. Брокгауз, И.А. Ефрон. М.: Изд-во Эксмо, 2006. - 672 с.

6. Даль, В.И. Толковый словарь русского языка. Современная версия. - М.: Из-д-во Эксмо, 2006. - 736 с. 